\title{
EDITORIAL
}

\section{LAS HERRAMIENTAS DEL NUEVO PARADIGMA DE LA SALUD EN EL SIGLO XXI: CIE /CIF}

\author{
Miguel Querejeta \\ Equipo de Valoración de Personas con Discapacidad. Dirección de Política Social. Diputación Foral de Gipuzkoa.
}

A pesar de que desde hace más de cincuenta años la OMS ya definió la salud como: "Un estado de completo bienestar físico, mental y social, y no solo la ausencia de enfermedad o dolencia", la realidad ha sido que los problemas relacionados con los estados alterados de salud se han venido midiendo invariablemente con modelos "biomédicos" y en parámetros de morbimortalidad exclusivamente. Hasta finales del siglo pasado la única clasificación de "referencia" para estudiar estos problemas, de la familia de clasificaciones de la OMS, era la CIE (con sucesivas actualizaciones, la última, su $10^{a}$ revisión de 1994). Pero desde la prematuridad hasta la enfermedad de Alzheimer, desde los trastornos depresivos hasta el SIDA, era cada vez más evidente que los datos que aportaba eran insuficientes para explicar realmente por qué ante idénticos diagnósticos las repercusiones sobre la salud de las personas eran totalmente diferentes.

La OMS se propuso pasar a un modelo de salud "biopsicosocial" para el siglo XXI y así

Correspondencia:

Miguel Querejeta

Equipo de Valoración de Personas con Discapacidad. Dirección de Política Social. Diputación Foral de Gipuzkoa Paseo de Zarategui 99 - Edificio Txara II

20015 San Sebastian

Telf: 943112661 Fax: 943112666

Correo electrónico: mquerejeta@gipuzkoa.net completar los "Dominios de la Salud" con parámetros que intenten reflejar el funcionamiento real de las personas dentro de su contexto. Parece lógico pensar que concepciones más evolucionadas de la salud requieran herramientas más complejas. Así en 2001 aprueba la CIF (Clasificación del Funcionamiento, de la discapacidad y de la salud) y la coloca en el centro de sus clasificaciones de "referencia", que desde entonces son dos: la CIE-10 y la CIF. Se contemplan como complementarias y pretenden ser el eje sobre el que se desarrollen las demás.

La OMS propone una visión de la salud, y por tanto del funcionamiento de las personas, desde una conceptualización holística, como la resultante de fundamentaciones biológicas, motivaciones psicológicas y condicionamientos sociales. Es también desde esta visión integradora de los tres anteriores elementos desde la que defiende el modelo bio-psico-social, para explicar ese hecho complejo y polifacético que es la discapacidad, pretendiendo establecer un lazo que armonice los tres niveles mediante una propuesta metodológica interactiva entre las funciones y estructuras del cuerpo, las actividades que realizan las personas y el contexto personal y ambiental en el que viven. La CIF propone, de forma novedosa, como termino "paraguas" para denominar a todos estos problemas interactuando, la palabra Discapacidad, distanciando su sig- 
nificado del que se le daba con anterioridad. Quizás todavía esta propuesta no ha sido bien entendida.

Lejos de cuestiones eufemísticas la OMS ha pretendido, fundamentalmente, acotar los campos de estudio de la salud. Así a través de la CIDDM en los 80 se pretendió clasificar "las consecuencias de la enfermedad" y se introdujo el concepto "handicap" con una connotación social, en cuanto a la "desventaja" que una persona (como consecuencia de una enfermedad, trastorno o deficiencia) podía presentar en relación a los demás. En España desventaja se tradujo por "minusvalía" y, hacia mediados de los ochenta pasó a sustituir al término oficial que había adquirido gran carga negativa y estigmatizante de "subnormalidad". Aunque la OMS enfatizó en la necesidad de separación entre los tres componentes presentes en el funcionamiento de las personas: el cuerpo (Deficiencias) las actividades (Discapacidades) y la parte social (Handicap/Minusvalía) en líneas generales no tuvo mucho éxito y en la mayoría de administraciones la tendencia fue (y sigue siendo) sintetizar los tres componentes en uno. En el caso de España en la palabra minusvalía, que se ha venido utilizando mayoritariamente para designar el componente corporal en vez del social. Así la gente entiende por "minusválida" a una persona con una deficiencia, más que la desventaja social como consecuencia de su deficiencia. España no fue el único país en el que ocurrió esto, por lo que la OMS se vio en la necesidad de buscar un término "paraguas" que representara a los tres. Y, después de diversos estudios y reuniones de consenso, decidió utilizar el de "Discapacidad". Así se refleja en la CIF-OMS 2001: se mantiene el término Deficiencia, para referirse a los problemas corporales, Limitación, para las actividades, y Restricción en la participación, social para referirse a estos últimos.

Pero la CIF no se limita a ser una mera herramienta estadística, clínica o de investi- gación de la salud, ni siquiera a ser un nuevo modelo y conceptualización de la discapacidad, sino que pretende ser parte esencial del cambio de paradigma de los "estados de salud" de los individuos y las poblaciones, y servir como plataforma de transformación de conceptos, diseño de políticas y cambios legislativos, tanto en el campo sanitario como en el social. Por otra parte la visión de la salud, el funcionamiento y la discapacidad como una experiencia universal y pluricultural, presenta unas marcadas directrices éticas para que su uso respete el valor inherente, la diversidad y la autonomía de las personas, y en este sentido también pude considerarse una herramienta de gran utilidad para promover el respeto de los derechos humanos.

La CIF se propone desde la multidisciplinaridad. Los campos de actuación pueden ser muy amplios y pueden ir desde el mas obvio de su aplicación en políticas sociosanitarias, hasta todos aquellos en los que se trate de evaluar el funcionamiento de las personas y su contexto, como en el caso de servicios de asistencia, compañías de seguros, evaluaciones judiciales, sistemas laborales, seguridad social, transportes, ayudas técnicas, modificaciones ambientales, prevención...

En el estado su conocimiento es todavía pequeño y su utilización escasa, sin embargo el legislador no ha sido ajeno a estas propuestas y ha ido dando los pasos necesarios para su progresiva incorporación a normativas y leyes. Así la mayoría de la legislación generada en estos primeros años de siglo relacionada con la discapacidad (Ley de igualdad de oportunidades, no discriminación y accesibilidad universal, Ley de protección de la Dependencia...) toma como principal referente o se adhiere al modelo propuesto por la CIF-OMS 2001. Este mismo año ha sido aprobada por la Comisión del Congreso de los Diputados Para las Políticas Integrales de la Discapacidad, celebrada el 17/02/09 la proposición 
no de ley, por la que se insta al Gobierno a impulsar las medidas necesarias para la aprobación de nuevos baremos que valoren la discapacidad de acuerdo con la Clasificación Internacional del Funcionamiento y la Discapacidad (CIF)

Sorprende, no obstante, la aparentemente poca repercusión, o cuando menos indiferencia, a la hora de actualización de las propuestas de la OMS por parte de estamentos estrictamente sanitarios. Lo cierto es que la CIE-10 después de 15 años todavía no se utiliza en España, salvo parcialmente en el campo de la salud mental. Y en el caso de la CIF tampoco ha habido especial interés, quizás el que la edición en castellano haya estado promovida y difundida desde un ministerio de "servicios sociales" ha sorprendido a más de un profesional del mundo estrictamente "sanitario", que consideraba la salud feudo exclusivo... quizás, también por lo anterior, para algunos haya sido motivo para considerarla como una herramienta exclusivamente de uso "social" y no de medición de la salud.

El excelente artículo especial sobre la CIF que aparece en el presente número de la Revista Española de Salud Publica resume con claridad los objetivos y potencialidad de la CIF colaborando sin duda a su difusión y conocimiento en medios sanitarios.

La utilidad de estas clasificaciones dependerá de su uso, en teoría de marcha lenta, pero cada vez más espoleada por la globalización y la necesidad de compartir información en el mismo lenguaje. La novedosa situación de unificar las competencias de sanidad y política social en un Ministerio puede ser una buena oportunidad de coordinar esfuerzos para profundizar en el binomio CIE-10/CIF propuesto por la OMS, que sin duda en un futuro no muy lejano enmarcará el escenario de un macrocambio global en la visión de la salud de los seres humanos. 
